University of Wollongong

Research Online

Faculty of Social Sciences - Papers (Archive) Faculty of Arts, Social Sciences \& Humanities

2014

ERP components and performance in the equiprobable Go/NoGo task: Inhibition in children

Robert Barry

University of Wollongong, rbarry@uow.edu.au

Frances M. De Blasio

University of Wollongong, francesd@uow.edu.au

Follow this and additional works at: https://ro.uow.edu.au/sspapers

Part of the Education Commons, and the Social and Behavioral Sciences Commons

Research Online is the open access institutional repository for the University of Wollongong. For further information contact the UOW Library: research-pubs@uow.edu.au 
ERP components and performance in the equiprobable Go/NoGo task: Inhibition in children

\author{
Abstract \\ Abstract presented at the 17th World Congress of Psychophysiology (IOP2014) of the International \\ Organization of Psychophysiology (IOP) Hiroshima, Japan, September 23rd to 27th, 2014 \\ Keywords \\ go, equiprobable, performance, components, inhibition, erp, task, children, nogo \\ Disciplines \\ Education | Social and Behavioral Sciences \\ Publication Details \\ Barry, R. J. \& De Blasio, F. M. (2014). ERP components and performance in the equiprobable Go/NoGo \\ task: Inhibition in children. International Journal Of Psychophysiology, 94 (2), 175.
}




\section{ERP components and performance in the equiprobable Go/NoGo task: Inhibition in children}

Robert J. Barry,

Frances M. De Blasio

University of Wollongong, Australia

We recently proposed a processing schema for adults in the equiprobable auditory Go/NoGo task, based on a PCA decomposition of their ERPs. We hypothesised that early sensory components, such as the N1, mark the start of the identification of the Go/NoGo stimulus. Subsequent categorisation of the stimulus as "NoGo" is associated with a frontal N2b, fronto-central P3a, and an enhanced late positivity (LP), while categorisation as "Go" is associated with a posterior N2c and P3b, andclassic Slow Wave (SW), representing directed processing related to response preparation and execution. In the absence of the dominant Go imperative found in the usual Go/NoGo task, our previous work had regarded this equiprobable task as involving little inhibitory processing. However, we were aware of the greater difficulty that children have in this task, apparent in their poorer reaction time (RT) performance and larger error rates, and wondered whether immature inhibition could be important. This study sought to investigate the existence of differential processing chains for Go and NoGo in children, and to use the individual's performance measures of RT and errors of omission and commission to illuminate the link between N2 and inhibition. Forty children aged between 8 and 13 (mean 10.4, SD 1.5) years participated in the study, which presented 4 stimulus blocks each containing 75 Go and 75 NoGo tone stimuli in random order. Mean Go and NoGo ERPs from all children were subjected to a temporal Principal Components Analysis with unrestricted VARIMAX rotation. The first 9 components explained $93.2 \%$ of the variance and were identified (in temporal order) as P1, N1, Processing Negativity (PN), frontal N2b, N2c, P3a, P3b, SW and a LP, similar to our adult findings. Most components were differentially enhanced to Go and NoGo as in adults, supporting the differential processing schema suggested by our adult study. The children's NoGo commission errors were correlated with the NoGo-enhanced frontal N2b. Larger N2b amplitudes were associated with fewer errors, supporting the inhibitory function of $N 2 b$ in children in this paradigm. 